\title{
Effect of yeast culture or cellulolytic enzymes in licking blocks on rumen fermentation and fibre degradation in vitro*
}

\author{
M.Y. Can, L. Wang, Q.X. Meng, L.P. Ren and Z.M. Zhou' \\ State Key Laboratory of Animal Nutrition, College of Animal Science and Technology, \\ China Agricultural University \\ Beijing100094, P.R. China
}

\begin{abstract}
An in vitro gas production experiment was conducted to determine the effect of yeast culture (YC) and cellulolytic enzyme (CE) included in urea-molasses-mineral (UMM) licking blocks on ruminal fermentation characteristics and fibre degradation of wheat straw. Five treatment blocks were: 1. control (CON, no UMM block added), 2. typical block (B), 3. yeast culture block (YCB), 4. cellulolytic enzyme block (CEB) and 5. yeast culture plus cellulolytic enzyme block (YCCEB). The results showed that gas production and both dry matter and cell wall degradabilities were significantly enhanced by supplemental UMM licking blocks $(\mathrm{P}<0.01)$, of which the greatest gas production and the fibre degradabilities were found with the treatment YCB, followed by YCCEB, $\mathrm{CEB}$, and B. It is concluded that yeast culture, cellulolytic enzymes or their combination included in licking blocks has a potential to boost rumen fermentation and fibre degradation.
\end{abstract}

KEY WORDS: UMM licking block, ruminal fermentation, gas production, degradation, in vitro

\section{INTRODUCTION}

Low quality crop residues, like wheat straw, are the primary energy source for ruminants during a considerable time of the year. Due to low contents of crude proteins $(<70 \mathrm{~g} / \mathrm{kg} \mathrm{DM})$ and high contents of cell walls, however, these residues are unpalatable and less degradable in the rumen. To optimize microbial fermentation of these residues, it is necessary to synchronize carbohydrate and

\footnotetext{
${ }^{*}$ Supported by National Outstanding Young Scientist Foundation, Grant No. 30125033 and National Natural Science Foundation of China, Grant No. 30270944

${ }^{1}$ Corresponding author: e-mail: zhouzhenming2001@sina.com
} 
protein supply and to supplement certain biologically active substances to the diet. It has well established that supplementing nitrogen, readily fermentable energy, minerals and monensin together in licking blocks improved rumen fermentation and nutrient utilization (Debasis and Singh, 2002). However, the data is limited about the effect of including cellulolytic enzymes (CE) or yeast culture (YC) in the licking blocks on rumen fermentation characteristics and fibre degradation.

Using an in vitro gas production technique, the present study was conducted to investigate the effect of including $\mathrm{YC}$ or $\mathrm{CE}$ in the licking blocks on rumen fermentation characteristics and fibre degradation.

\section{MATERIAL AND METHODS}

The urea-molasses-mineral (UMM) block was manufactured by using a special press (Model YTD32-315, Xuzhou Special Machine Tool Manufacture). The ingredients of UMM blocks were (on DM basis), \%: fine salt 38, urea 12, sugar cane molasses 6 , trace mineral premix 6 , zeolite 4 , bentonite $12, \mathrm{MgO} 4$, calcium carbonate 5, sodium sulphate 3 , dicalcium phosphate 5 , paraffin oil 2 , and additives 3. All ingredients were mixed in a stainless mixer and then pressed at the pressure of $25 \mathrm{MPa} / \mathrm{cm}^{2}$ for $0.8 \mathrm{~min}$. The size of each block was $22 \times 7 \mathrm{~cm}$ with a weight of approximately $5 \mathrm{~kg}$. All blocks after forming were covered with polyethylene film to prevent contamination.

Four different blocks were made with addition of different additives in this study: typical block (B, only bentonite as an additive), yeast culture block (YCB), cellulolytic enzyme block (CEB) and yeast culture plus cellulolytic enzyme block (YCCEB). The products of yeast culture and cellulolytic enzyme are obtained from some commercial companies. Yeast culture (Saccharomyces cerevisiae, Type Diamond V XP) is obtained from Diamond V Mills, Inc., Cedar Rapids, IA. The enzyme product, containing activities of cellulase, hemicellulase, xylanase, and amylase, is locally derived from Bacillus licheniformis, compliant with the specification for food-grade enzymes and generally recognized as safe in China. The inclusion percentages of additives in the blocks were 3\% for yeast culture, cellulolytic enzyme preparation, and both combinations (1.5\% yeast culture plus $1.5 \%$ cellulolytic enzymes). The typical block only contained $3 \%$ bentonite in replacement of the biological active substances.

The in vitro gas production experiment using UMM blocks and wheat straw used as a sole fibrous substrate was carried out based on the method of Menke and Steingass (1988). Dry samples of wheat straw (0.2 g) and licking blocks (25 mg licking block, in a powder form) were weighed into $100 \mathrm{ml}$ special calibrated glass syringes, added $30 \mathrm{ml}$ of anaerobic buffer- rumen fluid mixture solution, and incubated at $39^{\circ} \mathrm{C}$ for $72 \mathrm{~h}$ in an incubator equipped with a rotor. Five treatment 
incubations were performed: 1. control (CON, no UMM block added), 2. typical block (B), 3. yeast culture block (YCB), 4. cellulolytic enzyme block (CEB) and 5 . yeast culture plus cellulolytic enzyme block (YCCEB). The gas production was measured at the time intervals of $0,1,2,4,6,8,10,12,16,20,24,30,36,42$, $48,54,60,66$ and $72 \mathrm{~h}$, respectively. A part of syringes was taken out from the incubator at $48 \mathrm{~h}$ determination of dry matter and NDF degradation, ruminal $\mathrm{pH}$, $\mathrm{NH}_{3}-\mathrm{N}$ (Broderick and Kang, 1980), and VFA concentration by GC (Erwin et al., 1961; SP-3420, Beifen Ruili Analytical Equipment Co., Beijing).

Dynamic gas production parameters were calculated by non-linear Model in SAS (1999). The model was GP $=\mathrm{B} \times(1-\exp (-\mathrm{c} \times(\mathrm{t}-\mathrm{lag})))$. GP is gas production $(\mathrm{ml})$ of $0.2 \mathrm{~g}$ DM wheat straw sample (DM basis) at time t; B is potentially maximum gas production $(\mathrm{ml})$ of $0.2 \mathrm{~g}$ DM sample; c is rate of gas production $\left(\mathrm{h}^{-1}\right)$; Lag is delaying time of gas production $(\mathrm{h})$; $\mathrm{t}$ is time of incubation in vitro (h). All data was analysed using a completely randomized design nonlinear of procedures of SAS Institute Inc. (SAS, 1999). Significance level was set as $\mathrm{P}<0.05$ unless indicated otherwise. Data presented in the tables are in the form of mean values with the standard error of the difference.

\section{RESULT AND DISCUSSIONS}

As shown in Figure 1, in vitro gas production of wheat straw was significantly $(\mathrm{P}<0.01)$ influenced by supplemental UMM licking blocks. The fermentation pattern of gas production within $72 \mathrm{~h}$ incubation was similar among the five treatments. The greatest gas production was found in YCB, followed by CEB, YCCEB, CEB and B, with the lowest gas production in CON. The reason for higher gas production due to supplemental UMM licking blocks over control can be attributed to the supply of carbohydrates, nitrogen and minerals that are favourable

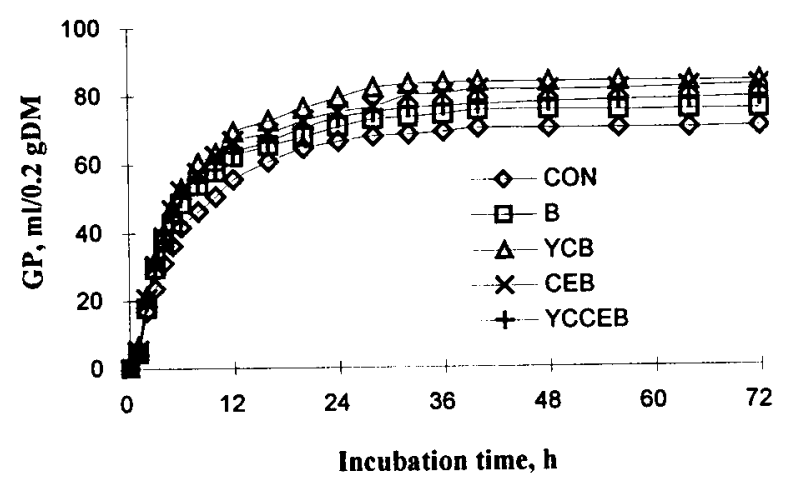

Figure 1. The dynamic gas production of wheat straw $(0.2 \mathrm{~g} \mathrm{DM})$ with different UMM blocks within $72 \mathrm{~h}$ of incubation. Data points represent the mean of gas production adjusted to $0.2 \mathrm{~g}$ dry substrate 
to rumen fibre fermentation. Moreover, yeast culture, cellulolytic enzymes or their combinations further increased ruminal gas production, suggesting stimulation of rumen fibre degradation by these biological substances, especially the yeast culture product. This result is well consisted with other observations (Moloney and Drennan, 1994; Callaway and Martin, 1997).

Fitting the mathematical model of GP $=\mathrm{B} \times\left(1-\exp -\mathrm{c}^{*}(\mathrm{t}-\mathrm{lag})\right)$ to these gas production data showed a satisfactory fit to the gas production data $\left(\mathrm{R}^{2}=0.97 \sim\right.$ 0.99 ; Table 1). The greatest potential gas production was found in the treatment YCB, followed by YCCEB, CEB, B and CON. Compared with the treatment of $\mathrm{CON}$ and $\mathrm{B}$, the treatment of YCB, YCCEB or CEB had faster $(\mathrm{P}<0.01)$ gas production rates. In contrast to the rate of gas production, the fermentation lag time showed a decreased order of: $\mathrm{YCCEB}<\mathrm{CEB}<\mathrm{YCB}<\mathrm{B}<\mathrm{CON}(\mathrm{P}<0.01)$.

Table 1. The amount and dynamic gas production of wheat straw with different UMM blocks $(0.2 \mathrm{~g}$ $\mathrm{DM}$ ) fermented within $72 \mathrm{~h}$ incubation in vitro

\begin{tabular}{lccccccc}
\hline \multirow{2}{*}{ Item } & \multicolumn{5}{c}{ Treatment } & \multirow{2}{*}{ SEM } & \multirow{2}{*}{$\mathrm{P}$} \\
\cline { 2 - 7 } & CON & $\mathrm{B}$ & YCB & CEB & YCCEB & & \\
\hline Total 72 h GP, ml/0.2 g DM & $67.37^{\mathrm{d}}$ & $70.80^{\mathrm{c}}$ & $79.27^{\mathrm{a}}$ & $73.03^{\mathrm{c}}$ & $76.73^{\mathrm{b}}$ & 1.27 & 0.001 \\
Potential GP, ml/0.2 g DM & $68.96^{\mathrm{d}}$ & $71.28^{\mathrm{c}}$ & $80.69^{\mathrm{a}}$ & $75.64^{\mathrm{b}}$ & $77.50^{\mathrm{b}}$ & 1.30 & 0.001 \\
Rate of GP/h & $0.078^{\mathrm{d}}$ & $0.143^{\mathrm{c}}$ & $0.156^{\mathrm{b}}$ & $0.163^{\mathrm{b}}$ & $0.184^{\mathrm{a}}$ & 0.03 & 0.001 \\
Lag time, h & $1.98^{\mathrm{a}}$ & $1.33^{\mathrm{b}}$ & $1.15^{\mathrm{c}}$ & $1.07^{\mathrm{c}}$ & $0.82^{\mathrm{d}}$ & 0.20 & 0.001 \\
\hline
\end{tabular}

The result of wheat straw degradation after $48 \mathrm{~h}$ fermentation is illustrated in Figure 2. The 48-h degradation rates of wheat straw were increased with supplement of UMM blocks. UMM block supplement showed higher $(\mathrm{P}<0.01)$ degradabilities of DM (IVDMD) and NDF (IVNDFD) than CON. Compared with CON, the supplement of B, YCB, CEB and YCCEB resulted in increased IVDMDs by $24.56,35.73,26.82$ and $29.32 \%$, respectively. However, there were no significant differences of IVDMD among the treatments of B, CEB and YCCEB $(\mathrm{P}>0.05)$. Similar to the results of IVDMD, the 48-h IVNDFD values of B, YCB, CEB and YCCEB were increased by $15.81,27.25,20.79$ and $24.67 \%$ over CON, respectively. Furthermore, compared with treatment B, the treatment of YCB, CEB

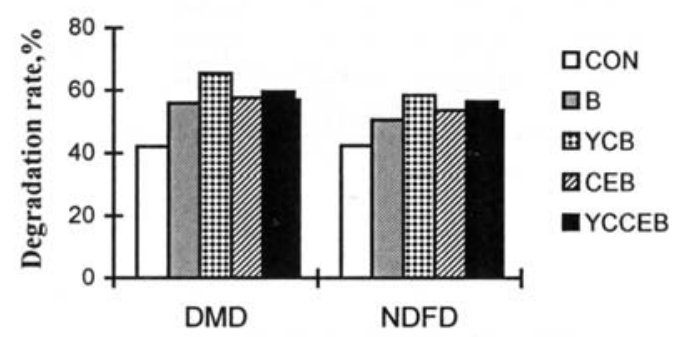

Figure 2. Effect of supplement of UMM blocks on 48-h IVDMD and IVNDF of wheat straw 
and YCCB had higher $(\mathrm{P}<0.05)$ IVNDFD. This result further demonstrated that improvement of degradation by supplemental UMM licking blocks, especially those containing yeast culture, cellulolytic enzymes or their combinations. Yoon and Stem (1996) also observed that yeast culture may provide soluble growth factors (i.e. maltate, organic acid, B vitamins, and amino acid), that are required by ruminal bacteria for growth.

The data of fermentation parameters after $48 \mathrm{~h}$ fermentation are presented in Table 2. Supplement of UMM licking blocks decreased $(\mathrm{P}<0.01)$ ruminal $\mathrm{pH}$, but there was no difference in rumen $\mathrm{pH}$ values among UMM block treatments $(\mathrm{P}>0.05)$. Ruminal concentration of $\mathrm{NH}_{3}-\mathrm{N}$ was significantly affected by supplemented UMM blocks $(\mathrm{P}<0.01)$. Compared with treatment $\mathrm{B}$, supplement of yeast culture, cellulolytic enzyme, or their combination in the UMM blocks significantly $(\mathrm{P}<0.05)$ increased ruminal $\mathrm{NH}_{3}-\mathrm{N}$ concentrations.

The total VFA concentration and the individual VFA molar proportions were prominently affected by supplemented UMM blocks $(\mathrm{P}<0.01)$. Among the supplemental blocks, the greatest VFA concentration was found in $\mathrm{YCB}$, followed by YCCEB, CEB, and B at last. As to individual VFA molar proportions, compared with CON, supplement of UMM blocks significantly decreased the proportion of acetate $(\mathrm{P}<0.01)$, but significantly $(\mathrm{P}<0.05)$ increased the percentages of propionate and butyrate. Compared with treatment $\mathrm{B}, \mathrm{YCB}, \mathrm{CEB}$ and YCCEB also increased $(\mathrm{P}<0.01)$ the percentage of propionate. Compared with $\mathrm{CON}$, treatments of $\mathrm{B}$, $\mathrm{YCB}, \mathrm{CEB}$ and YCCEB also significantly decreased the percentages of isobutyrate, isovalerate and valerate $(\mathrm{P}<0.05)$.

Table 2. Effect of supplemental UMM blocks on ruminal fermentation parameters of wheat straw

\begin{tabular}{|c|c|c|c|c|c|c|c|}
\hline \multirow{2}{*}{ Item } & \multicolumn{5}{|c|}{ Treatment } & \multirow{2}{*}{ SEM } & \multirow{2}{*}{$\mathrm{P}$} \\
\hline & $\mathrm{CON}$ & $\mathrm{B}$ & YCB & CEB & YCCEB & & \\
\hline$p H$ & $6.73^{\mathrm{a}}$ & $6.55^{\mathrm{b}}$ & $6.51^{\mathrm{b}}$ & $6.48^{\mathrm{b}}$ & $6.48^{\mathrm{b}}$ & 0.46 & 0.001 \\
\hline $\mathrm{NH}_{3}-\mathrm{N}, \mathrm{mg} / 100 \mathrm{ml}$ & $7.50^{\mathrm{c}}$ & $26.34^{\mathrm{a}}$ & $20.94^{b}$ & $22.09^{b}$ & $18.17^{\mathrm{c}}$ & 3.87 & 0.001 \\
\hline TVFA, mmol/1 & $35.91^{\mathrm{c}}$ & $52.25^{\mathrm{b}}$ & $63.80^{\mathrm{a}}$ & $53.88^{\mathrm{b}}$ & $58.99^{\mathrm{b}}$ & 4.50 & 0.001 \\
\hline \multicolumn{8}{|c|}{ VFA proportion, mol\% } \\
\hline acetate & $71.54^{\mathrm{a}}$ & $64.36^{\mathrm{b}}$ & $61.36^{\mathrm{c}}$ & $61.37^{\mathrm{b}}$ & $64.86^{\mathrm{c}}$ & 1.87 & 0.001 \\
\hline propionate & $14.92^{\mathrm{d}}$ & $20.07^{\mathrm{b}}$ & $21.82^{\mathrm{a}}$ & $20.10^{\mathrm{b}}$ & $19.99^{\mathrm{c}}$ & 1.17 & 0.001 \\
\hline butyrate & $7.44^{\mathrm{d}}$ & $11.19^{\mathrm{c}}$ & $12.57^{\mathrm{b}}$ & $14.16^{\mathrm{a}}$ & $10.92^{\mathrm{c}}$ & 1.23 & 0.001 \\
\hline isobutyrate & $1.49^{\mathrm{a}}$ & $1.24^{\mathrm{b}}$ & $1.16^{\mathrm{c}}$ & $1.19^{\mathrm{c}}$ & $1.07^{\mathrm{d}}$ & 0.70 & 0.021 \\
\hline isovalerate & $2.84^{\mathrm{a}}$ & $1.93^{\mathrm{b}}$ & $1.88^{\mathrm{b}}$ & $1.89^{\mathrm{b}}$ & $1.99^{\mathrm{b}}$ & 0.19 & 0.011 \\
\hline valerate & $1.77^{\mathrm{a}}$ & $1.21^{\mathrm{b}}$ & $1.21^{\mathrm{b}}$ & $1.29^{\mathrm{b}}$ & $1.17^{\mathrm{c}}$ & 0.45 & 0.016 \\
\hline
\end{tabular}




\section{CONCLUSIONS}

Yeast culture, cellulolytic enzymes or their combinations included in ureamolasses-mineral licking blocks enhanced gas production, rumen ammonia and VFA concentrations and fibre degradation, when wheat straw was used as a sole fibrous source. These results indicate that yeast culture, cellulolytic enzymes or their combination included in the licking blocks has a potential to boost rumen fermentation and fibre degradation.

\section{REFERENCES}

Broderick G.A., Kang J.H., 1980. Automated simultaneous determination of ammonia and amino acids in ruminal fluids and in vitro media. J. Dairy Sci. 63, 64-75

Callaway E.S., Martin S.A., 1997. Effect of a Saccharomyces cervisiae culture on ruminal that utilize lactate and digest cellulose. J. Dairy Sci. 80, 2035-2044

Debasis D., Singh G.P., 2002. Monensin enriched urea molasses mineral block on feed intake, nutrient digestibility and blood glucose in cattle fed on wheat straw based diet. Asian-Austr. J. Anim. Sci. 15, 1579-1584

Erwin E.S., Marco G.J., Emery E.M., 1961. Volatile fatty acid analyses of blood and rumen fluid by gas chromatography. J. Dairy Sci. 44, 1768-1771

Menke K.H., Steingass H., 1988. Estimation of the energetic feed value obtained from chemical analysis and in vitro gas production using rumen fluid. Anim. Res. Develop. 28, 7-55

Moloney A.P., Drennan M.J., 1994. The influence of the basal diet on the effects of yeast culture on ruminal fermentation and digestibility in steers. Anim. Feed Sci. Tech. 50, 55-73

SAS, 1999. SAS/STAT ${ }^{\circledR}$ User's Guide (Release 8.2). SAS Institute Inc. Cary, NC

Yoon I.K., Stem M.D., 1996. Effect of Saccharomyces cervisiae and Aspergillus oryzae culture on ruminal fermentation in dairy cows. J. Dairy Sci.79, 411-417 